\title{
1, 2, 3 SEM: Teaching Scanning Electron Microscopy to Community College Faculty and Staff
}

N.A. Butkevich, ${ }^{*}$ R. Weinkauf,**

* Biology Department, Schoolcraft College, 18600 Haggerty Road, Livonia, MI 48152-2696

** Instructional Division, Schoolcraft College, 18600 Haggerty Road, Livonia, MI 48152

Schoolcraft College is a community college located in Livonia, Michigan. The total student enrollment tops 36,000. Schoolcraft serves the southeastern Michigan counties of Wayne, Oakland, Washtenaw and primarily surrounding Detroit suburbs. It serves as a feeder school for University of Michigan-Dearborn, Wayne State University, Eastern Michigan University, Madonna University and Lawrence Technological University.

Can the SEM serve as a catalyst for sparking interest in multidisciplinary projects and college initiatives? At Schoolcraft College, the SEM is applied to strengthening basic science and critical thinking skills, fostering partnerships, and stimulating interest in scientific inquiry and research. The SEM is being used to transform learning experiences for students, faculty and staff.

The first step in creating this transformational learning experience was to train faculty and staff to use the SEM. Two faculty and one staff member received 40 hours of initial training from the microscope manufacturer. The next step was to train additional faculty and staff members from a variety of disciplines to use the SEM. As a result, a four hour introductory SEM workshop was developed.

The introductory workshop introduces participants to the theory, applications and controls of the microscope. Electron beam and specimen interactions are discussed. Operation of the microscope to image and analyze samples using the secondary electron detector is emphasized. Participants also learn basic organic and inorganic specimen preparation, including sputter coating of organic specimens.

Upon Successful completion of the workshop, the participants should be able to:

-Prepare organic and inorganic samples for SEM imaging and analysis

-Explain electron beam and specimen interactions

-Determine optimum imaging parameters and settings based upon the sample's composition and properties

-Operate the SEM and related controls to image and analyze organic and inorganic samples using the secondary electron detector

At the end of this concise four hour workshop, participants receive an image acquisition and sputter coater certification. In addition, successful completion of the workshop entitles participants to 
schedule supervised open lab time for use of the SEM and sample preparation equipment. This enables a wide range of faculty and staff to incorporate the SEM into their classes, projects and college initiatives.

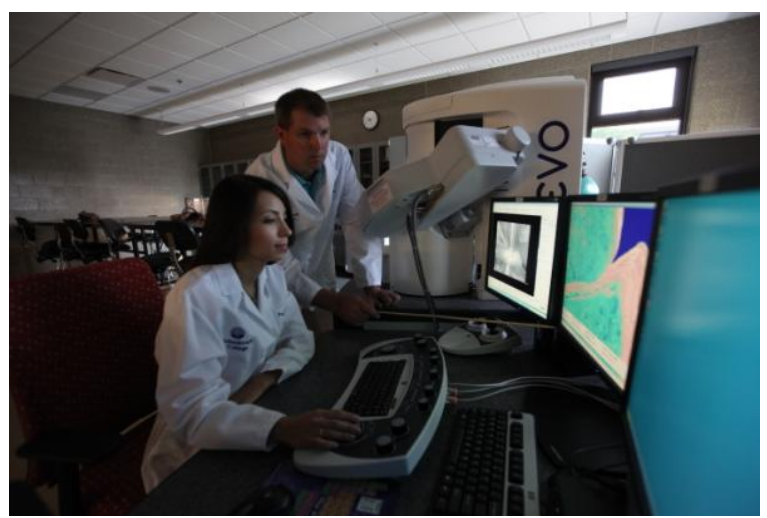

FIG. 1. Faculty and staff using the Zeiss EVO LS-15 microscope.

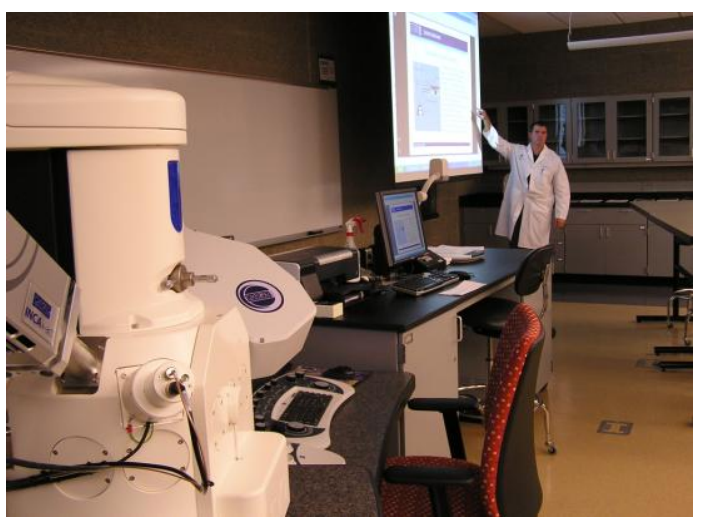

FIG. 2. The SEM facilities at Schoolcraft College. 